\title{
Factors Associated with Occupational Hearing Loss among Stone- Mortar Workers in Phayao Province, Northern Thailand
}

\author{
Sakesun Thongtip, Ph.D., Sarawut Sangkham, M.P.H. ${ }^{1}$, Rattikarn Sukpromson, M.N.S. ${ }^{2}$ \\ 'Department of Environmental Health, School of Medicine, University of Phayao, Mueang, Phayao 56000, Thailand. \\ ${ }^{2}$ Department of Occupational, Phayao Hospital, Mueang, Phayao 56000, Thailand.
}

Received 13 January 2020 • Revised 7 March 2020 • Accepted 15 March $2020 \bullet$ Published online 13 May 2020

\begin{abstract}
:
Objective: Noise pollution is an unwanted phenomenon that affects human health and can lead to occupational hearing loss in exposed workers. The stone-mortar industry is one of the processes which can create a noise hazard. This study aimed to explore the factors associated with occupational hearing loss among stone-mortar workers in Phayao Province, Northern Thailand.
\end{abstract}

Material and Methods: A cross-sectional study was conducted 27 stone-mortar workers who were interviewed with a questionnaire. Pure-tone hearing thresholds were measured using audiometry. The data were analyzed using MannWhitney U test, Spearman's rank correlation test and Kruskal-Wallis test and Multiple linear regression analysis.

Results: The study found a significant difference between age and high frequency hearing loss in both right and left ears (p-values 0.024 and 0.049 , respectively). There were significant correlations between working hours per day and high frequency hearing loss in both right and left ears ( $p$-values 0.030 and 0.042 , respectively). Multiple linear regression analysis found increasing age was associated with high frequency hearing loss in both right and left ears ( $p$-values 0.033 and 0.017 , respectively) after adjusting for number of years worked, working hours per day, and use of personal protective equipment as random variables.

Conclusion: All stone-mortar factories produce noise pollution. Therefore, the local policy makers should emphasize reducing noise pollution from stone factories and surveillance of occupational hearing loss to improve the quality of life of the people who work in such factories.

Keywords: occupational hearing loss, stone-mortar workers

Contact: Sakesun Thongtip, Ph.D.

Department of Environmental Health, School of Medicine, University of Phayao,

Mueang, Phayao 56000, Thailand.

E-mail: sake_115@hotmail.com

(c) 2020 JHSMR. Hosting by Prince of Songkla University. All rights reserved.

This is an open access article under the CC BY-NC-ND license

(http://www.jhsmr.org/index.php/jhsmr/about/editorialPolicies\#openAccessPolicy).
J Health Sci Med Res 2020;38(3):213-219 doi: $10.31584 /$ jhsmr.2020740 www.jhsmr.org 


\section{Introduction}

Noise pollution is a major environmental risk to human health and quality of life. Exposure to noise can cause adverse health effects, including increased risk of cardiovascular diseases, hypertension, psychological effects and hearing loss in workers and people living close to noise sources. ${ }^{1-6}$ A study from India reported that the level of disabling hearing loss in adults was $16.0 \%$ worldwide, ranging from $7.0 \%$ to $21.0 \%$ in various subregions. ${ }^{7}$ There are both natural and artificial sources of noise pollution, arising from things such as exploitation of natural resources, construction, transportation, agriculture, and industrial activities. $^{8-10}$

Short-term exposure to loud noise can also cause temporary hearing loss. Long term exposure to loud noise can lead to permanent hearing loss through damage to the inner ear (cochlea) or auditory neural system., ${ }^{5,11,12}$

In Thailand, noise-induced hearing loss is a significant health problem in the industrial and agricultural industries. ${ }^{8,13}$ One such industry is the stonemortar industry, which depends largely on informal labor with lack of access to health services and preventive programs. ${ }^{8,14}$ The stone mortar factories generate loud noise from the production process and use machines which create various types of noise pollution. Early detection of hearing loss is a necessary step in providing appropriate control and health system programs for people who have suffered hearing loss. Therefore, we aimed to assess frequency hearing levels among stonemortar workers in Phayao province, northern Thailand.

\section{Material and Methods}

This study was a cross-sectional study to explore factors associated with occupational hearing loss among stone-mortar workers, conducted from July to August 2018 in Ban Sang sub-district, Phayao province, Thailand. We enrolled 27 subjects from all available stone-mortar workers by using a purposive sampling method. The inclusion criteria were subjects who were 18 years old and above and had worked in a stone-mortar factory for at least one year. Workers who could not verbally communicate in the Thai language or who had neuropathy were enrolled.

All participants signed informed consent forms before data collection. The study was approved by the Research Ethics Committee of the University of Phayao, Thailand (No. 2/029/61). The questionnaire gathered information on the demographic and work characteristics of the participants, including sex, age, education, marital status, income, number of years worked and working hours per day, and use of personal protective equipment (PPE).

Pure-tone hearing thresholds at the frequencies of $500,1,000,2,000,3,000,4,000,6,000$ and 8,000 Hertz $(\mathrm{Hz})$ were measured using audiometry (Manufacturer: ENTOMED screening audiometer, Model: SA201). Frequency averages of $500,1,000$, and $2,000 \mathrm{~Hz}$ were classified as low frequency, while frequency averages of 3,000, 4,000, and $6,000 \mathrm{~Hz}$ were classified as high frequency. ${ }^{9,15}$ The cutpoint for hearing loss did exceed safe cut-off levels recommended by Occupational Safety and Health Administration (OSHA) guidelines [25 decibels $(\mathrm{dB})$ or more]. ${ }^{16-18}$

The data were analyzed using the $\mathrm{R}$ program. Mann-Whitney U test, Spearman's rank correlation test and Kruskal-Wallis test were used to compare demographic characteristics (sex, age education, marital status, income, number of years worked, working hours per day, and use of PPE). Multiple linear regression analysis was used to analyze the association between age and high frequency hearing levels. Statistical significance was set at $p$-value< 0.05 .

\section{Results}

The participants were 24 males (88.9\%) and 3 females $(11.1 \%)$. The average age was 51.1 years with an 
average income of 7,347.8 baht per month and an average of 18.8 years worked. The most common personal protective equipment used were ear plugs 14 respondents, $51.9 \%$, cotton balls 10 respondents, $37.0 \%$, and ear muffs 3 respondents, $11.1 \%$ (Table 1 ).

The study found that the average hearing levels of the right and left ears were decreased at 500, 3,000, $4,000,6,000$, and $8,000 \mathrm{~Hz}$ when compared with a hearing loss of up to 25 decibels. ${ }^{16-18}$ The average hearing level of both right and left ears were normal at 1,000 and 2,000 Hz. The cutpoint for hearing loss did exceed safe cut-off levels recommended by OSHA guidelines (25 dB or more) (Table 2)..$^{16-18}$

Table 1 Characteristics of study participants $(n=27)$

\begin{tabular}{ll}
\hline Characteristic & Number $(\%)$ \\
\hline Sex & \\
Male & $24(88.9)$ \\
$\quad$ Female & $3(11.1)$ \\
Age (years), mean \pm S.D. & $51.1 \pm 8.8$ \\
$\quad<60$ & $22(81.5)$ \\
$\geq 60$ & $5(18.5)$ \\
Education & \\
$\quad \leq$ Primary school & $22(81.5)$ \\
$>$ Primary school & $5(18.5)$ \\
Marital status & \\
Married & $26(96.3)$ \\
Single/divorced & $1(3.7)$ \\
Income (baht/month) & $7,347.8 \pm 2,166.0$ \\
$<7,500$ & $13(48.1)$ \\
$\geq 7,500$ & $14(51.9)$ \\
Number of years worked & $18.8 \pm 15.1$ \\
$<10$ & $11(40.7)$ \\
$\geq 10$ & $16(59.3)$ \\
Working hours per day & $7.2 \pm 1.5$ \\
Cotton balls & $10(37.0)$ \\
Ear plugs & $3(11.1)$ \\
\hline &
\end{tabular}

S.D. $=$ standard deviation
Table 2 Average hearing levels at varying frequencies $(\mathrm{Hz})$

\begin{tabular}{llll}
\hline Variable & $\begin{array}{l}\text { Frequency } \\
(\mathbf{H z})\end{array}$ & Mean \pm S.D. & Min-Max \\
\hline Right ear & 500 & $30.6 \pm 7.4$ & $15-50$ \\
& 1,000 & $20.9 \pm 6.2$ & $10-30$ \\
& 2,000 & $19.6 \pm 12.7$ & $0-50$ \\
& 3,000 & $32.6 \pm 19.7$ & $0-70$ \\
& 4,000 & $42.4 \pm 20.2$ & $0-75$ \\
& 6,000 & $43.0 \pm 24.9$ & $0-85$ \\
& 8,000 & $41.1 \pm 24.4$ & $0-85$ \\
& 500 & $28.7 \pm 8.6$ & $0-95$ \\
& 1,000 & $18.0 \pm 6.8$ & $10-30$ \\
& 2,000 & $16.7 \pm 10.5$ & $0-50$ \\
& 3,000 & $29.6 \pm 18.9$ & $5-65$ \\
& 4,000 & $41.5 \pm 18.4$ & $0-70$ \\
& 6,000 & $43.0 \pm 24.7$ & $0-85$ \\
8,000 & $38.9 \pm 23.5$ & $5-85$ \\
\hline
\end{tabular}

$\mathrm{Hz}=$ hertz, S.D.=standard deviation, Min=minimum, Max=maximum

The average high frequency hearing losses of the right and left ears were $39.3 \pm 18.9$ and $38.0 \pm 17.9 \mathrm{~dB}$, respectively. Average low frequency hearing losses of the right and left ears were $23.7 \pm 7.7$ and $21.1 \pm 6.9 \mathrm{~dB}$ respectively. The cutpoint for hearing loss did exceed safe cut-off levels recommended by OSHA guidelines (25 dB or more) (Table 3). ${ }^{16-18}$

The study found a significant difference between age and high frequency hearing loss of the right and left ears ( $p$-values 0.024 and 0.049 , respectively). There were significant differences between sex and high frequency hearing loss of the right ear $(p-$ value $=0.034)$. Moreover, there was significant correlation between working hours per day and high frequency hearing loss in both right and left ears ( $p$-value $=0.030$ and $p$-value $=0.042$, respectively) (Table 4). 
Table 3 Average hearing levels of low and high frequencies $(\mathrm{Hz})$

\begin{tabular}{lll}
\hline Hearing level & Mean \pm S.D. & Min-Max \\
\hline Right ear & & \\
Low frequency & $23.7 \pm 7.7^{*}$ & $8.3-40.0$ \\
High frequency & $39.3 \pm 18.9^{*}$ & $6.7-73.3$ \\
Left ear & & \\
Low frequency & $21.1 \pm 6.9^{*}$ & $10.0-40.0$ \\
High frequency & $38.0 \pm 17.9^{*}$ & $5.0-70.0$ \\
\hline
\end{tabular}

$\mathrm{Hz}=$ hertz, S.D.=standard deviation, Min=minimum, Max=maximum, *Low frequencies in right and left ears compared with high frequency by Spearman's rank correlation test with $p$-value $<0.05$
The multiple linear regression analysis showed that increased age was not associated with low frequency hearing loss in either ears (right and left ears $p$-value= 0.272 and $p$-value $=0.065$, respectively) after adjusting for number of years worked, working hours per day, and personal protective equipment as random variables (Table 5).

The multiple linear regression analysis showed that increased age was associated with high frequency hearing loss of both ears (right and left ears $p$-value $=0.033$ and $p$-value $=0.017$, respectively) after adjusting for number of years worked, working hours per day, and personal protective equipment as random variables (Table 6).

Table 4 Factors associated with low frequency and high frequency hearing levels

\begin{tabular}{|c|c|c|c|c|}
\hline \multirow{2}{*}{ Characteristic } & \multicolumn{2}{|c|}{ Low frequency ( $p$-value) } & \multicolumn{2}{|c|}{ High frequency ( $p$-value) } \\
\hline & Right ear & Left ear & Right ear & Left ear \\
\hline \multicolumn{5}{|l|}{ Sex $x^{a}$} \\
\hline $\begin{array}{l}\text { Male } \\
\text { Female }\end{array}$ & 0.333 & 0.130 & $0.034^{*}$ & 0.177 \\
\hline \multicolumn{5}{|l|}{ Age $(\text { years })^{a}$} \\
\hline $\begin{array}{l}<60 \\
\geq 60\end{array}$ & $0.042^{*}$ & 0.109 & $0.024^{*}$ & $0.049^{\star}$ \\
\hline \multicolumn{5}{|l|}{ Education $^{\mathrm{a}}$} \\
\hline $\begin{array}{l}\leq \text { Primary school } \\
\text { >Primary school }\end{array}$ & 0.150 & 0.103 & 0.169 & 0.080 \\
\hline \multicolumn{5}{|l|}{ Marital status ${ }^{a}$} \\
\hline $\begin{array}{l}\text { Married } \\
\text { Single/Divorced }\end{array}$ & 0.334 & 0.272 & 0.440 & 0.521 \\
\hline \multicolumn{5}{|l|}{ Income (baht/month) ${ }^{a}$} \\
\hline $\begin{array}{l}<7,500 \\
\geq 7,500\end{array}$ & 0.609 & 0.733 & 0.981 & 0.356 \\
\hline \multicolumn{5}{|l|}{ Number of years worked ${ }^{a}$} \\
\hline $\begin{array}{l}<10 \\
\geq 10\end{array}$ & 0.255 & 0.107 & 0.079 & $0.026^{*}$ \\
\hline Working hours per day ${ }^{\mathrm{b}}$ & 0.223 & 0.267 & $0.030^{*}$ & $0.042^{*}$ \\
\hline Hours working (per day) ${ }^{b}$ & 0.470 & 0.162 & 0.872 & 0.970 \\
\hline \multicolumn{5}{|c|}{ Personal protective equipment used ${ }^{c}$} \\
\hline $\begin{array}{l}\text { Cotton balls } \\
\text { Ear plugs } \\
\text { Ear muffs }\end{array}$ & 0.076 & 0.243 & 0.444 & 0.541 \\
\hline
\end{tabular}

${ }^{a}$ Presented in Mann-Whitney $U$ test, ${ }^{\text {bS}}$ Spearman's rank correlation test, ${ }^{\circ}$ Kruskal-Wallis test, ${ }^{*} \mathrm{p}$-value $<0.05$ 
Table 5 Association between age and low frequency hearing levels using multiple linear regression analysis

\begin{tabular}{|c|c|c|c|c|c|c|}
\hline \multirow{2}{*}{$\begin{array}{l}\text { Associated factors } \\
(n=27)\end{array}$} & \multicolumn{3}{|c|}{ Low frequency of right ear } & \multicolumn{3}{|c|}{ Low frequency of left ear } \\
\hline & B & SE & $p$-value & B & SE & p-value \\
\hline Age (years) & 0.207 & 0.183 & 0.272 & 0.332 & 0.171 & 0.065 \\
\hline
\end{tabular}

Adjusted for number of years worked, working hours per day, and personal protective equipment as random variables, ${ }^{*} p-v a l u e<0.05$, $\mathrm{B}=$ beta, $\mathrm{SE}=$ standard error

Table 6 Association between age and hearing level in high frequency using multiple linear regression analysis

\begin{tabular}{|c|c|c|c|c|c|c|}
\hline \multirow{2}{*}{$\begin{array}{l}\text { Associated factors } \\
(n=27)\end{array}$} & \multicolumn{3}{|c|}{ High frequency of right ear } & \multicolumn{3}{|c|}{ High frequency of left ear } \\
\hline & B & SE & $p$-value & B & SE & p-value \\
\hline Age (years) & 1.026 & 0.450 & $0.033^{*}$ & 1.083 & 0.420 & $0.017^{\star}$ \\
\hline
\end{tabular}

Adjusted for number of years worked, working hours per day, and personal protective equipment as random variables, ${ }^{*} p-v a l u e<0.05$, $\mathrm{B}=$ beta, $\mathrm{SE}=$ standard error

\section{Discussion}

The stone-mortar industry is an informal labor sector which generates very loud noise during the production process. Long term exposure to this noise affects physical health, mental health and quality of life, including leading to various diseases such as tinnitus, cardiovascular disease, hypertension, and hearing loss. ${ }^{19-23}$

Our study found that most stone-mortar workers used ear plugs $(51.9 \%)$ or cotton balls $(37.0 \%)$ to try to reduce their noise exposure. Previous studies have found that most workers lacked awareness about noise-induced hearing loss. Thus, hearing protectors should be provided engineering controls, administrative controls, and work practices for reducing noise exposure to safe levels. ${ }^{1,8,12}$

Our study found that average high frequency hearing loss of both right and left ears were higher than those of OSHA guidelines (25 decibels). ${ }^{16-18}$ The average age of the stone-mortar workers in our study was 51.1 years, and we found a significant difference between age and high frequency hearing loss of right and left ears. Our study found that there was a significant correlation between working hours per day and high frequency hearing loss of both ears. Moreover, the multiple linear regression analysis showed that increased age was associated with high frequency hearing loss of both ears. These findings were consistent with our findings that association of age, long working hours and hearing impairment in high frequencies. Therefore, there are many possible confounding the possible confounding variables due to unmeasured factors. ${ }^{24,25}$

The main limitation of this study was its crosssectional design exploring risk factors among the study group, stone-mortar workers, but with no control group. Therefore, a longitudinal study is needed to confirm if there actually is a causal relationship between risk factors such as noise exposure level and occupational hearing loss. 


\section{Conclusion}

Noise pollution is an unwanted phenomenon that affects human health and occupational hearing losses in exposed workers. Our results suggest that age and working time period are the strongest risk factors for this type of hearing loss. Therefore, concerned government maybe provide protection devices for at-risk workers. In addition, policy local makers should emphasize reducing noise pollution from stone factories and surveillance of occupational hearing loss to improve the workers' quality of life.

\section{Acknowledgement}

We thank the factory managers and stone-mortar workers who participated in this research for their cooperation.

\section{Conflict of interest}

None

\section{References}

1. Nandi SS, Dhatrak SV. Occupational noise-induced hearing loss in India. Indian J Occup Environ Med 2008;12:53-6.

2. Pelegrin AC, Canuet L, Rodriguez AA, Morales MP. Predictive factors of occupational noise-induced hearing loss in Spanish workers: a prospective study. Noise Health 2015;17:343-9.

3. Hammersen F, Niemann H, Hoebel J. Environmental noise annoyance and mental health in adults: findings from the cross-sectional German Health Update (GEDA) study 2012. Int J Environ Res Public Health 2016;13:E954.

4. Hahad O, Kröller-Schön S, Daiber A, Münzel T. The cardiovascular effects of noise. Dtsch Arztebl Int 2019;116:24550.

5. Li X, Dong Q, Wang B, Song H, Wang S, Zhu B. The influence of occupational noise exposure on cardiovascular and hearing conditions among industrial workers. Sci Rep 2019;9: 11524.

6. Abbasi M, Monazzam MR, Akbarzadeh A, Zakerian SA, Ebrahimi $\mathrm{MH}$. Impact of wind turbine sound on general health, sleep disturbance and annoyance of workers: a pilot- study in Manjil wind farm, Iran. J Environ Health Sci Eng 2015; 13:71.

7. Nelson DI, Nelson RY, Concha-Barrientos M, Fingerhut M. The global burden of occupational noise-induced hearing loss. Am J Ind Med 2005;48:446-58.

8. Fuente A, Hickson L. Noise-induced hearing loss in Asia. Int J Audiol 2011;50(Suppl 1):S3-10.

9. Kitcher ED, Ocansey G, Tumpi DA. Early occupational hearing loss of workers in a stone crushing industry: our experience in a developing country. Noise \& Health 2012;14:68-71.

10. de Paiva Vianna KM, Alves Cardoso MR, Rodrigues RM. Noise pollution and annoyance: an urban soundscapes study. Noise \& Health 2015;17:125-33.

11. Ryan AF, Kujawa SG, Hammill T, Le Prell C, Kil J. Temporary and permanent noise-induced threshold shifts: a review of basic and clinical observations. Otol Neurotol 2016;37:e271-5.

12. National Institute for Occupational Safety and Health (NIOSH). Occupational noise exposure [homepage on the Internet]. Georgia: NIOSH; 2014 [cited 2019 Dec 1]. Available from: https://www.cdc.gov/niosh/docs/98-126/default.html

13. Wongsuwan K, Rattanaarun K, Kittiwannawong K. Prevalence of noise-induced hearing loss in workers with noise exposure in Panyananthaphikkhu Chonprathan Medical Center, Srinakharinwirot University. J Health Sci Med Res 2019;37: 81-92.

14. Akazili J, Chatio S, Ataguba JE-O, Agorinya I, Kanmiki EW, Sankoh O, et al. Informal workers' access to health care services: findings from a qualitative study in the KassenaNankana districts of Northern Ghana. BMC Int Health Hum Rights 2018;18:20.

15. Mirza R, Kirchner DB, Dobie RA, Crawford J. Occupational noise-induced hearing loss. J Occup Environ Med 2018;60: e498-501.

16. Occupational Safety and Health Administration. Recording criteria for cases involving occupational hearing loss [homepage on the Internet]. Washington, D.C.: OSHA; 2019 [cited 2019 Dec 1]. Available from: https://www.osha.gov/awsregs/regulations/standardnumber/1904/1904.10

17. Summacheeva Foundation. Guideline for standardization and interpretation of audiometry in occupational health setting [homepage on the Internet]. Chonburi: Summacheeva Foundation; 2018 [cited 2019 Dec 1]. Available from: http:// 
safetyhubs.com/wp-content/uploads/2018/11/book_audio metry.pdf

18. Rabinowitz PM, Slade M, Dixon-Ernst C, Sircar K, Cullen M. Impact of OSHA final rule--recording hearing loss: an analysis of an industrial audiometric dataset. J Occup Environ Med 2003;45:1274-80.

19. Seidman MD, Standring RT. Noise and quality of Life. Int J Environ Res Public Health 2010;7:3730-8.

20. Basner M, Babisch W, Davis A, Brink M, Clark C, Janssen $S$, et al. Auditory and non-auditory effects of noise on health. Lancet 2014;383:1325-32.

21. Azadboni ZD, Talarposhti RJ, Ghaljahi M, Mehri A, Aarabi $S$, Poursadeghiyan $M$, et al. Effect of occupational noise exposure on sleep among workers of textile industry. J Clin Diagn Res 2018;12:LC18-21.

22. Abbasi M, Monnazzam MR, Zakerian S, Yousefzadeh AJF Letters N. Effect of wind turbine noise on workers' sleep disorder: a case study of Manjil wind farm in northern Iran. Fluct Noise Lett 2015;14. doi: 10.1142/S0219477515500200.

23. Abbasi M, Farhang-Dehghan S, Yazdanirad S, Mehri A, Kolahdouzi M, Fallah Madvari R, et al. Assessment of role of job components and individual parameters on the raised blood pressure in a noisy industry. Arch Acoust 2019;44:57584.

24. Park JW, Park JS, Kim S, Park M, Choi H, Lim S. The association between long working hours and hearing impairment in noise unexposed workers: data from the $5^{\text {th }}$ Korea National Health and Nutrition Examination Survey (KNHANES 2010-2012). Ann Occup Environ Med 2016;28:55.

25. El Dib RP, Silva EMK, Morais JF, Trevisani VFM. Prevalence of high frequency hearing loss consistent with noise exposure among people working with sound systems and general population in Brazil: a cross-sectional study. BMC Public Health 2008;8:151. 